\title{
A distance education experience on assessment of airway maneuvers during COVID-19 pandemic
}

\author{
M. Murat Oktay ${ }^{1}$, Mustafa Boğan ${ }^{2}$, Mustafa Sabak ${ }^{3}$, Hasan Gümüşboğa ${ }^{4}$, İbrahim Bilir ${ }^{5}$, \\ Mehmet Cihat Demir ${ }^{2}$, Hüseyin Narcı ${ }^{6}$ \\ ${ }^{1}$ Hasan Kalyoncu University, Gaziantep, Turkey; ${ }^{2}$ Emergency Department, Health Research and Application \\ Hospital, Düzce University, Düzce, Turkey; ${ }^{3}$ Emergency Department, Nizip State Hospital, Gaziantep, \\ Turkey; ${ }^{4}$ Emergency Department, Şehitkamil State Hospital, Gaziantep, Turkey; ${ }^{5}$ Department of \\ Nursing, Faculty of Health Sciences, Hasan Kalyoncu University, Turkey; \\ ${ }^{6}$ Emergency Department, Mersin University, Mersin, Turkey
}

\begin{abstract}
Background and objectives: The coronavirus disease 2019 (COVID-19) pandemic has necessitated the switch to distance education by abandoning face-to-face education worldwide. This study aimed to investigate whether it is possible for practical education and performance measurements through distance education.

Methods: The application video and the application steps were sent to the participants through their smartphone by WhatsApp messenger. Grade 1 students in the Physiotherapy Section (Group A) and Grade 1 students in the Paramedic Section (Group B) voluntarily participated in the study. The participants were asked to apply simulation applications and record the simulation applications' video clips with their smartphones.

Results: The mean age of the 123 participants was $20.11 \pm 2.03$ (18-33) years, and 56 (45.5\%) were in Group A, and 67 (54.5\%) were in Group B. While the participants in Group A were successful at a rate of $35.7 \%(n=20)$ in the head tilt-chin lift maneuver, this rate was $65.7 \%(n=$ 44) for Group B ( $p=0.001)$. For the jaw thrust maneuver, the success rate was $21.4 \%(n=12)$ for Group A and 31.3\% ( $n=21)$ for Group B.

Conclusion: In this study, the participants used family members as a live simulation model in our research. The participants who were given face-to-face education before were more successful on head tilt chin lift maneuver. Jaw thrust maneuver was more challenging to learn and practice by distance education. The academicians interested in medical education should keep in mind that the outcomes of the COVID-19 pandemic have permanent effects on education systems.
\end{abstract}

IMC J Med Sci 2021; 15(1): 001

\section{Introduction}

The coronavirus disease 2019 (COVID-19) pandemic has necessitated the switch to distance education through abandoning face-to-face education worldwide [1-2]. Distance education models have been used in medical education during the recent 30 years; distance practical education is still a problem [3-7]. On the other hand, useful and reliable methods could not be developed to evaluate distance education efficiency [7].

Basic Life Support (BLS) is among the most common practical education by using technological items [810]. In didactic medical education models, airway maneuvers are taught on models by an

*Correspondence: Mustafa Boğan, Emergency Department, Health Research and Application Hospital, Düzce University, Düzce, Turkey, Posta code: 81620. Email: mustafabogan@hotmail.com 
experienced instructor, in addition to theoretical educations [11]. Practical education is the main difficulty of distance education systems. In this study, we aimed to teach the airway maneuvers [the head tilt-chin lift (HTCL) maneuver and the jaw thrust (JT) maneuver] by distance education, and to evaluate by video clips which content practical application of the participants on a family member. It was also aimed at integrated simulation education to distance education in accordance with the education needs that have changed abruptly during the COVID-19 pandemic.

\section{Methods}

Ethics committee approval was obtained from Hasan Kalyoncu University (date: 24.04.2020, decision number: 2020/017) before the study. Informed written consent was obtained from all participants. Grade 1 students in the Physiotherapy Section (Group A) and Grade 1 students in the Paramedic Section (Group B) voluntarily participated in the study. Two airway maneuvers (HTCL and JT) were taught and evaluated. The participants in Group A received no education for airway maneuvers. The researchers gave the participants in Group B face-to-face education three months before the study ( 4 week, 2 hours in a week). These two groups were compared as they were the only students who had completed the credit of this lesson concurrently in the semester when the schools went on holiday due to the pandemic. Both groups were given about one hour of presentations separately through the Adobe Connect video conference program. During these presentations, the participants were taught airway maneuvers on the models.
Furthermore, a 94-sec application video was created by the researcher, and the application steps were sent to the participants via WhatsApp Messenger. The participants were asked to apply these maneuvers on a relative or a family member within 15 days and record it on the cell phone (during the study, there was quarantine in our country). The recorded videos were sent to the researchers by e-mail.

According to the Global Quality score, the quality of the videos sent by the participants was evaluated (Table-1). Videos with a Global Quality score of 4 and 5 were assessed in terms of content. The records of the participants who did not send the video record on time and the videos which were shorter than $30 \mathrm{sec}$ and more prolonged than 180 sec were excluded.

The application steps were scored separately (Table-2 and Table-3). While evaluating the videos, each application step was scored as "1 point" if it was done correctly and "0 points" if it was not done correctly. Both applications were evaluated in 8 sub-steps. Each participant received a minimum of " 0 " and a maximum of " 8 " points from the applications. The participant who got eight full points from an application was considered successful; the participant who got $<8$ points was unsuccessful. The videos were scored separately by two independent observers (two emergency medicine specialists with a minimum of 5 years of experience) using a rubric. Pearson Correlation test was used to determine rater reliability, which shows consistency between raters. Analysis results showed a high correlation between raters $(r=0.90$; $\mathrm{p}<0.05$ ).

Table-1: Global Quality score

\begin{tabular}{cl}
\hline Score & \multicolumn{1}{c}{ Description } \\
\hline 1. & Poor quality, poor flow of the site, most information missing, not at all useful for patients \\
2. & $\begin{array}{l}\text { Generally poor quality and poor flow, some information listed but many important topics } \\
\text { missing, of very limited use to patients }\end{array}$ \\
3. Moderate quality, suboptimal flow, some important information is adequately discussed but \\
others poorly discussed, somewhat useful for patients \\
4. $\quad \begin{array}{l}\text { Good quality and generally good flow. Most of the relevant information is listed, but some } \\
\text { topics not covered, useful for patients }\end{array}$ \\
5. Excellent quality and flow, very useful for patients
\end{tabular}


Table-2: Head tilt chin lift assessment steps

\begin{tabular}{llc}
\hline & \multicolumn{1}{c}{ Head tilt chin lift (HTCL) } & Correct/Wrong \\
\hline 1. & He/she stood in a proper position & $1 / 0$ \\
2. & He/she stated that he/she was sure that there was no trauma & $1 / 0$ \\
3. & The patient was placed in supine position & $1 / 0$ \\
4. & He/she placed the left hand at the hairline level & $1 / 0$ \\
5. & He/she held the mandible with the index finger and middle finger of the right & $1 / 0$ \\
& hand & $1 / 0$ \\
6. He/she moved the mandible up when the head was pushed backwards & $1 / 0$ \\
7. He/she put the neck in extension at the same time & $1 / 0$ \\
8. He/she expressed all steps verbally & \\
\hline
\end{tabular}

Table-3: Jaw thrust assessment steps

\begin{tabular}{llc}
\hline \multicolumn{1}{c}{ Jaw thrust (JT) } & Correct/Wrong \\
\hline 1. He/she stood in a proper position (positioned from the occipital region of the & $1 / 0$ \\
patient's head and face so as to be in front) & He/she reported the presence or suspicion of trauma (neck ecchymosis, \\
abrasion, etc.) & $1 / 0$ \\
3. The patient was placed in supine position & $1 / 0$ \\
4. He/she placed the 2, 3, 4 and the 5 fingers of both hands on the right angulus & $1 / 0$ \\
5. He/she placed the thumbs of both hands on the chin & $1 / 0$ \\
6. He/she moved the chin up with the $2,3,4$ and 5 fingers of both hands at the & $1 / 0$ \\
7. He/she opened the mouth by pushing the chin with thumbs of both hands & $1 / 0$ \\
8. He/she expressed all steps verbally & $1 / 0$ \\
\hline
\end{tabular}

The two groups were compared according to gender, duration of the videos, HTCL and JT score, success level of HTCL and JT.

\section{Statistical Analysis}

The normality distribution of the data was evaluated with the Shapiro Wilk test. The Student's t test was used for comparison of two independent normally distributed groups and the Mann Whitney $U$ test was used for comparison of two independent non-normally distributed groups. The associations between categorical variables were analyzed with the Pearson and exact chi-square tests. Pearson Correlation test was used to determine rater reliability, which shows consistency between raters. For the descriptive statistics, the mean \pm standard deviation was used for the numerical variables, and numbers and percentages were used for the categorical variables. Statistical analyses were carried out using the SPSS Windows version 24.0 package program and a $p$ level of $<0.05$ was accepted as statistically significant.

\section{Results}

Out of 129 students, the video records of 3 from Group A and 3 from Group B were excluded as they did not meet the inclusion criteria; hence, the study was completed with 123 participants including, 56 participants from Group A and 67 from Group B. The mean age of the participants was $20.11 \pm 2.03$ (18-33) years. Of the participants, 42 (34.1\%) were males, and 81 (65.9\%) were females. The mean 
Table-4: Descriptive and comparative data

\begin{tabular}{|c|c|c|c|}
\hline Parameter & General (n = 123) & Group A $(n=56)$ & Group B $(n=67)$ \\
\hline $\begin{array}{l}\text { Age (year) } \\
{[\text { Mean } \pm \text { SD (min-max)] }}\end{array}$ & $20.11 \pm 2.03(18-33)$ & - & - \\
\hline \multicolumn{4}{|l|}{ Gender } \\
\hline Male & $n=42 ; 34.1 \%$ & $n=23 ; 41.1 \%$ & $n=19 ; 28.4 \%$ \\
\hline Female & $n=81 ; 65.9 \%$ & $n=33 ; 58.9 \%$ & $n=48 ; 71.6 \%$ \\
\hline $\begin{array}{l}\text { Duration of video (sec) } \\
\text { [Mean } \pm \text { SD }(\min -\max )]\end{array}$ & $59.9 \pm 17.1(34-122)$ & $52.5 \pm 12.57(34-78)$ & $52.5 \pm 12.57(34-78)$ \\
\hline HTCL (score) & $7.24 \pm 1.06(3-8)$ & $6.87 \pm 1.24(3-8)$ & $7.55 \pm 0.77(5-8)$ \\
\hline$[$ Mean $\pm S D(\min -\max )]$ & & & ${ }^{*} p=0.001$ \\
\hline $\begin{array}{l}\text { JT (score) } \\
{[\text { Mean } \pm \text { SD (min-max)] }}\end{array}$ & $6.83 \pm 1.01(4-8)$ & $6.70 \pm 1.01(4-8)$ & $\begin{array}{c}6.92 \pm 1.01(4-8) \\
p=0.176\end{array}$ \\
\hline $\begin{array}{l}\text { Success level of HTCL } \\
\text { Successful }\end{array}$ & $(n=64 ; 52 \%)$ & $(n=20 ; 35.7 \%)$ & $(n=44 ; 65.7 \%)$ \\
\hline Unsuccessful & ( $n=59 ; 48 \%)$ & $(n=36 ; 64.3 \%)$ & $\begin{array}{c}(n=23 ; 34.3 \%) \\
\quad{ }^{*} p=0.001\end{array}$ \\
\hline $\begin{array}{l}\text { Success level of JT } \\
\text { Successful }\end{array}$ & $(n=33 ; 26.8 \%)$ & $(n=12 ; 21.4 \%)$ & $(n=21 ; 31.3 \%)$ \\
\hline Unsuccessful & $(n=90 ; 73.2 \%)$ & $(n=44 ; 78.6 \%)$ & $\begin{array}{c}(\mathrm{n}=46 ; 68.7 \%) \\
p=0.216\end{array}$ \\
\hline
\end{tabular}

JT - jaw thrust; HTCL - head tilt chin lift; *p - level of significance.

duration of video recordings was $59.9 \pm 17.1$ seconds. A mean of $7.24 \pm 1.06$ (3-8) steps out of 8 steps of the HTCL maneuver had been applied correctly and, a mean of $6.83 \pm 1.01$ (4-8) steps out of 8 steps of the JT maneuver had been applied correctly. While the participants in Group A were successful at a rate of $35.7 \%(n=20)$ for the $\mathrm{HTCL}$ maneuver, this rate was $65.7 \%(n=44)$ for Group B, and the difference was statistically significant $(p=$ 0.001 ). The success rate was low in both groups for the JT maneuver; the success rate was $21.4 \%$ ( $n=$ 12) for Group $A$ and $31.3 \%(n=21)$ for Group $B$ (Table-4). While the participants in Group B performed a mean of $7.55 \pm 0.77$ out of 8 steps of the HTCL maneuver correctly, this was $6.87 \pm 1.24$ for Group A, and the difference was statistically significant. The success rates were similar for the JT maneuver in both groups $(p=0.176)($ Table-4).

\section{Discussion}

COVID-19 has led to a radical paradigm change in medical education and has mandated the switch to distance education systems worldwide [12]. Many education institutions have provided medical education through platforms such as Zoom, Tencent Conference, Ding Talk. Furthermore, concurrent PowerPoint applications have been used during teleconferences, and some new systems have been tried [1,13-15]. There are studies in the literature proposing that developing novel learning objects for distance education are mandatory [16]. Consistent with these studies, in our research, we made online PowerPoint presentations through the video conference program. The participants could ask questions online and made contributions. We also supported the presentations with video sharing. 
Studies have reported that some methodological innovations are required for to develop the students' knowledge and skills in distance education environments [13-17]. The studies toward developing novel education paradigms are mostly based on comparison of didactic education systems and distance education systems. Gallagher et al. determined that students who received webbased distance education demonstrated better attendance and motivation [18]. In the study of Sarıhan et al. comparing two emergency medicine resident groups who had received traditional and video-assisted education, no significant difference was found between the groups concerning pre-test and post-test scores [19]. Bernard et al. evaluated the studies investigating learning methods between 1985 and 2002 and found that distance education models achieved better learning [20]. However, some education models, which use both didactic education systems and distance education systems, are also available [21,22]. Our study compares distance education procedures (Group A) and blended education procedures (Group B). In our research, while there was no difference between the groups about the JT maneuver, Group $B$, the complex education group, yielded better results for the HTCL maneuver. In this regard, our study results are consistent with those of studies proposing that complex education systems that integrate didactic learning models and distance education systems positively influence learning $[22,23]$. One of the most critical distance education problems is feedback and testing of lesson elements $[7,24]$. Assessments of the performance were mostly made with traditional methods in many studies comparing e-education models and traditional education models. Our study, the participants recorded their applications on videos through cell phones, and their learning performances were evaluated through these videos. Hence, we could show that a performance assessment criterion could be developed for distance education by assessing videos recorded by the participants. It is possible to state that although simple, this is a methodological innovation type under pandemic conditions, and it is one of the unique aspects of our study. On the other hand, this was mandatory for us under pandemic conditions despite limited evidence about the effectiveness of offline video applications on elearning [25]. However, it should be stated that the duration of the application videos recorded by the researchers and participants were shorter than the 5-7 $\mathrm{min}$ reported in the literature [24].

Learning-teaching through the simulation method, has taken an important place in medical education in recent years. Hybrid models, live animals and inorganic simulators are the frequently used materials for this purpose $[26,27]$. The popularity of this education model, which aims to provide knowledge about difficult or impossible practices to apply to patients, is gradually increasing. In recent years, growing progressively inorganic simulators and simulation educations have taken an important place in medical education, since they do not lead to ethical problems, by being repeatable and having high error tolerance [28]. Use of live human models may lead to ethical issues due to patient safety $[28,29]$. On the contrary to many simulation studies, the participants used family members as a simulation model in our research. In this regard, our study has contributed to practical training during the pandemic period, which began abruptly and caught education systems unaware.

Barsuk et al. showed that the medical student group which received practical education through a simulator was more successful in airway management [30]. Birt et al. did not detect a difference between the two groups of paramedic students, one of which received a classical education for removing foreign bodies in the airway and another received distance education with telephone and plastic laryngoscopes obtained with a 3D printer [31]. In our study, which yielded practice training through live models, the finding of similar results in the two groups about the JT maneuver is consistent with the studies that have proposed that learning through e-education only is an effective way of learning [32]. The participants in both groups mostly made errors in the $6^{\text {th }}$ step of the JT maneuver. This is the step that is frequently taken incorrectly by the participants, also during face-to-face training. The subject should repeat the procedure several times; besides, he/she needs to be instructed individually. Studies propose that formal assessment systems are insufficient in medical education [33]. We suggest that it is an 
advantageous method in hands-on training as it is possible to monitor learning, provide feedback to the student, and provide assessment data for the teacher. Studies are proposing that online lessons of the formal assessment methods are also possible [33-35]. We could not apply formal methods individually online due to the pandemic's restricted time. We suggest that this is a factor that plays a role in the low $(<30 \%)$ success rates in both groups.

On the other hand, it should be remembered that the evaluation of this application in which four fingers of both hands uphold the jaw is difficult through cell phone videos. Although the comparison of HTCL and JT maneuvers seems to be inconsistent, the results are already inconsistent and abortive in many studies that have compared distance education with traditional teachinglearning approaches [36]. It appears that simulation educations should be integrated with distance education. Designing distance simulation education with physical objects and models in our study and in other studies suggests that we are at the beginning of this integration. Studies indicate that medical education practices may be carried out using joysticks and 360 VR (virtual reality eyeglasses) as in many high technology games and applications $[37,38]$. We consider that generalizing and standardization of this method would facilitate for distance simulation education efforts.

Due to the restricted time, the steps that were misapplied by the participants could only be discussed with them individually online. Not asking for a second video after the application has led to a limitation concerning performance assessment. Furthermore, the satisfaction of the participants could not be evaluated.

In this study, the participants used family members as a live simulation model in our research. The participants who were given face-to-face education before were more successful on Head Tilt Chin Lift. Jaw Thrust maneuver was more challenging to learn and practice by distance education.

The academicians interested in medical education should keep in mind that the outcomes of the COVID-19 pandemic have permanent effects on education systems. The COVID-19 pandemic has necessitated the development of a novel education paradigm based on information technologies. The need for integration of simulation education with distance education has also emerged during this process. Although our study indicates that distance hands-on training may be practical, it is also an example of assessing this education. We consider that virtual reality applications could contribute to medical education, and further studies should be conducted on this issue.

Authorship: $\mathrm{MB}$ and $\mathrm{MMO}$ contributed to conception; $\mathrm{MM}$ and $\mathrm{MMO}$ contributed to design; $\mathrm{MMO}, \mathrm{MS}$ and $\mathrm{HN}$ contributed to supervision; IB and $\mathrm{MS}$ contributed to data collection and processing; $\mathrm{HN}, \mathrm{MCD}$ and $\mathrm{HG}$ contributed to analysis and interpretation; $\mathrm{MB}$ and $\mathrm{MMO}$ contributed to literature review; $\mathrm{MMO}$ and $\mathrm{HN}$ contributed to writing; and MMO, MB, $\mathrm{HN}$ contributed to critical review.

Funding: The author(s) received no financial support for the research, authorship, and/or publication of this article.

Conflict of interest: The author(s) declared no potential conflicts of interest with respect to the research, authorship, and/or publication of this article.

Human rights: Authors declare that human rights were respected according to Declaration of Helsinki.

\section{References}

1. Srinivasan DK. Medical students' perceptions and an anatomy teacher's personal experience using an e-learning platform for tutorials during the Covid-19 crisis. Anat Sci Edu. 2020; 13(3): 318-319.

2. Evans DJR, Bay BH, Wilson TD, Smith CF, Lachman N, Pawlina W. Going virtual to support anatomy education: a STOPGAP in the midst of the Covid-19 pandemic. Anat Sci Edu. 2020; 13(3): 279-283.

3. Garrison DR. E-learning in the 21st century: a framework for research and practice. Taylor \& Francis. 2011. 
4. Clark RC, Mayer RE. E-learning and the science of instruction: proven guidelines for consumers and designers of multimedia learning. John Wiley \& Sons. 2016.

5. Kassebaum DK, Hendricson WD, Taft T, Haden NK. The dental curriculum at North American dental institutions in 2002-03: a survey of current structure, recent innovations, and planned changes. J Dent Educ. 2004; 68(9): 914-931.

6. Sinclair PM, Kable A, Levett-Jones T, Booth D. The effectiveness of internet-based e-learning on clinician behaviour and patient outcomes: a systematic review. Int J Nurs Stud. 2016; 57: 70-81.

7. Aksoy E, Izzetoglu K, Baysoy E, Agrali A, Kitapcioglu D, Onaral B. Performance monitoring via functional near infrared spectroscopy for virtual reality based basic life support training. Front Neurosci. 2019; 13 1336.

8. Matten CE, Shear T, Vender JS. Nonintubation management of the airway: airway maneuvers and mask ventilation. In: Hagberg CA, editor. Benumof's Airway Management: Principle and Practice. 3rd ed. Philadelphia, PA: SaundersElsevier; 2013. pp. 324-339.

9. Atanelov Z, Rebstock SE. Nasopharyngeal airway. In: StatPearls. StatPearls Publishing, Treasure Island (FL). 2018

10. Davies JD, Costa BK, Asciutto AJ. Approaches to manual ventilation. Respir Care. 2014; 59(6) 810-824.

11. Youngquist ST, Henderson DP, Gausche-Hill M, Goodrich SM, Poore PD, Lewis RJ. Paramedic self-efficacy and skill retention in pediatric airway management. Acad Emerg Med. 2008, 15(12): 1295-1303.

12. Okuda Y, Bryson EO, DeMaria S Jr, Jacobson L, Quinones J, Shen B, et al. The utility of simulation in medical education: what is the evidence? Mt Sinai J Med. 2009; 76(4) 330-343.

13. Kanneganti A, Sia CH, Ashokka B, Ooi SBS Continuing medical education during a pandemic: an academic institution's experience. Postgrad Med J. 2020; 96(1137): 384-386.
14. Rose $S$. Medical student education in the time of COVID-19. JAMA. 2020; 323(21): 2131.

15. Elizabeth, J. Covid and well being - productive use of lock down time. 2020. Available at SSRN: https://ssrn.com/abstract $=3598856$ or http://dx.doi.org/10.2139/ssrn.3598856.

16. Racheva V. Social aspects of synchronous virtual learning environments. AIP Publishing LLC. 2018; 2048(1): 020032.

17. McCutcheon K, Lohan M, Traynor M, Martin D. A systematic review evaluating the impact of online or blended learning vs. face-to-face learning of clinical skills in undergraduate nurse education. J Adv Nurs. 2015; 71(2): 255-270.

18. Gallagher JE, Dobrosielski-Vergona $\mathrm{KA}$ Wingard RG, Williams TM. Web-based vs. traditional classroom instruction in gerontology: a pilot study. J Dent Hyg. 2005; 79(3): 7

19. Sarıhan A, Oray NC, Güllüpınar B, Yanturali $S$, Atilla R, Musal B. The comparison of the efficiency of traditional lectures to videosupported lectures within the training of the Emergency Medicine residents. Turk J Emerg Med. 2016; 16(3): 107-111.

20. Bernard RM, Abrami PC, Lou Y, Borokhovski E, Wade A, Wozney L. How does distance education compare with classroom instruction? a meta-analysis of the empirical literature. Rev Educ Res. 2004; 74(3): 379-439.

21. Ruiz JG, Mintzer MJ, Leipzig RM. The impact of E-learning in medical education. Acad Med. 2006; 81(3): 207-212.

22. Garrison DR, Kanuka H. Blended learning: uncovering its transformative potential in higher education. Internet High Educ. 2004; 7(2): 95-105.

23. Auerbach $M$, Brown $L$, Whitfill $T$, Baird J, Abulebda K, Bhatnagar A, et al. Adherence to pediatric cardiac arrest guidelines across a spectrum of fifty Emergency Departments: a prospective, in situ, simulation based Study. Acad Emerg Med. 2018; 25(12): 1396-1408.

24. Hawthorne K, Prout H, Kinnersley P, Houston $\mathrm{H}$. Evaluation of different delivery modes of an 
interactive e-learning programme for teaching cultural diversity. Patient Educ Couns. 2009; 74(1): 5-11.

25. Regmi K, Jones L. A systematic review of the factors - enablers and barriers - affecting elearning in health sciences education. BMC Med Educ. 2020; 20: 1-18.

26. Silverplats K, Jonsson A, Lundberg L. A hybrid simulator model for the control of catastrophic external junctional haemorrhage in the military environment. Advances in Simulation. 2016; 1(1): 1-5.

27. Eisenburger $P$, Safar $P$. Life supporting first aid training of the public-review and recommendations. Resuscitation. 1999; 41(1): 3-18.

28. Ziv SD, Small PRWA. Patient safety and simulation-based medical education. Med Teach. 2000; 22(5): 489-495.

29. Binstadt ES, Walls RM, White BA, Nadel ES, Takayesu JK, Barker TD, et al. A comprehensive medical simulation education curriculum for emergency medicine residents. Ann Emerg Med. 2007; 49(4): 495-504.

30. Barsuk D, Ziv A, Lin G, Blumenfeld A, Rubin O, Keidan I, et al. Using advanced simulation for recognition and correction of gaps in airway and breathing management skills in prehospital trauma care. Anesth Analg. 2005; 100(3): 803-809.

31. Birt J, Moore E, Cowling MA. Piloting mobile mixed reality simulation in paramedic distance education. In N. Rodrigues, J. L. Vilaca, N. Dias, K. Wong, S. de Freitas, \& D. Duque (Eds.), 2017 IEEE 5th International Conference on Serious Games and Applications for Health. 2017; 1-8.

32. Aryal KR, Pereira J. E learning in surgery. Indian J Surg. 2014; 76(6): 487-493.

33. Walsh K. Point of view: online assessment in medical education - current trends and future directions. Malawi Mel J. 2015; 27(2): 71.

34. 34. Wood D. Formative assessment. In: Swanwick T, (editor). Understanding medical education: evidence, theory and practice. 2nd Eds. USA: John Wiley \& Sons, 2010.

35. Boulet JR, Durning SJ. What we measure and what we should measure in medical education. Med Educ. 2019; 53(1): 86-94.

36. Childs S, Blenkinsopp E, Hall A, Walton G. Effective e-learning for health professionals and students--barriers and their solutions. A systematic review of the literature--findings from the HeXL project. Health Info Libr J. 2005; 22(2): 20-32.

37. Kühnapfel UG, Kuhn C, Hubner M, Krumm H, Maa H, Neisius B. The Karlsruhe endoscopic surgery trainer as an example for virtual reality in medical education. MITAT. 1997; 6(2): 122125.

38. Falah J, Khan S, Alfalah T, Alfalah SFM, Chan W, Harrison DK, et al. Virtual reality medical training system for anatomy education. 2014 Science and Information Conference. 2014; 752-758. 